\title{
Web Data Extraction Dalam Analitika Data Audit: Pengembangan Artefak Teknologi Dalam Perspektif Design Science Research
}

\author{
Agung Darono \\ Kementerian Keuangan Republik Indonesia, DKI Jakarta \\ Email: agungdarono@kemenkeu.go.id
}

(Naskah masuk: 31 Agu 2020, direvisi: 21 Sep 2020, diterima: 13 Okt 2020)

\begin{abstract}
Abstrak
Perkembangan implementasi Teknologi Informasi dan Komunikasi (TIK) sebagai bagian pengendalian internal organisasi mendorong auditor mengembangkan analitika data audit (ADA/Audit Data Analytics) sebagai kerangka pengetahuan dan praktik untuk mendapatkan bukti audit dan informasi lainnya dari sekumpulan data elektronik terkait dengan pelaksanaan pada semua tahapan pekerjaan audit. Pada saat yang sama, terdapat kecenderungan organisasi untuk menyajikan datanya dengan aplikasi berbasis web. Terkait dengan keberadaan laman web sebagai sumber data (bukti audit) tersebut, telah berkembang teknik ekstraksi data dari laman web yang disebut dengan web data extraction. Penelitian ini dengan menggunakan design science research methodology mengajukan temuan artefak yang berkaitan dengan model dan instantiasi (instantiation) web data extraction untuk implementasi ADA. Hasil penelitian ini diharapkan dapat menjadi tambahan referensi dalam ranah praktik audit berupa artefak dalam bentuk instantiasi penggunaan web data extraction untuk akusisi data sebagai bukti audit dengan sumber dari halaman web, baik dari aplikasi berbasis intranet ataupun internet. Penelitian ini juga berkontribusi dengan mengajukan kerangka praktikal implementasi web data extraction sebagai bagian dari ADA dalam melaksanakan pekerjaan audit. Selain itu, hasil kajian ini juga diharapkan menjadi referensi untuk penggunaan design science research methodology yang ternyata belum terlalu banyak diaplikasikan dalam penelitian dalam disiplin audit di Indonesia.
\end{abstract}

Kata Kunci: akses, akusisi, artefak, instantiasi, kerangka kerja.

\section{Web Data Extraction in Audit Data Analytics: an Artifact Development in Design Science Research Perspective}

\begin{abstract}
Implementation of information technology as part of an organization's internal control has encouraged auditors to develop an Audit Data Analytics (ADA) as a conceptual and practical framework in obtaining useful information from a set of electronic data related to auditing engagement at all stages. At the same time, there is a tendency for organizations to provide their data using web-based applications. Concerning the webpages as a source of data (audit evidence), data extraction techniques from webpages called "web data extraction" have developed. Using design science method, this study proposes the artifact findings related to the model and instantiation of web data extraction applications for ADA implementation. The results of this study are expected to provide an additional reference in audit practices in the form of artifacts through the instantiation of the web data extraction to acquire data originating from webpages. It has also given a contribution by proposing a conceptual framework for the position of web data extraction and ADA in the audit concepts and practices. The results of this study are also expected to be a reference for the use of design science method methodology, as it has not been widely applied in the audit research in Indonesia.
\end{abstract}

Keywords: access, acquisition, artifact, framework, instantitation. 


\section{PENDAHULUAN}

Audit sebagai sebuah praktik yang independen untuk menguji keandalan suatu laporan atau informasi berdasarkan serangkaian evaluasi bukti harus menghadapi kenyataan bahwa bukti tersebut semakin didominasi oleh bukti berupa data elektronik yang dihasilkan oleh sistem informasi berbasis komputer $[1,2]$. Situasi yang demikian ini pada gilirannya mendorong para auditor untuk mengimplementasikan audit data analytics sehingga memungkinkan auditor untuk lebih mudah mengumpulkan bukti audit dalam bentuk informasi elektronik untuk kemudian melakukan penilaian risiko dan pengujian audit $[3,4,5]$. Tulisan ini menggunakan istilah "Analitika Data Audit" (selanjutnya: ADA) sebagai serapan dari istilah "Audit Data Analytics". AICPA menyatakan bahwa ADA adalah teknik untuk melaksanakan berbagai prosedur audit termasuk penilaian risiko (risk assessment), pengujian pengendalian, pengujian substantif hingga penarikan kesimpulan hasil audit [6]. ADA diharapkan membantu auditor untuk lebih efektif dan efisien dalam melakukan audit. Perkembangan lanskap bisnis saat ini bahkan menjadikan ADA sebagai komponen utama untuk mentranformasi praktik audit $[3,7,8]$.

Salah satu sumber data yang dapat digunakan untuk pekerjaan audit adalah laman web (web page) yaitu tampilan yang dihasilkan sistem aplikasi berbasis teknologi informasi dan komunikasi dengan format Hypertext Markup Langauge (HTML) dengan memuat bermacam-macam format data seperti teks, gambar, tabel, video, suara, click-path, koordinat, emoticon atau format data lainnya $[9,10,11]$. Web page, baik yang ditampilkan dalam jaringan privat organisasi (intranet) atau melalui jaringan publik World Wide Web (WWW/internet), merupakan salah satu sumber data yang dapat menjadi bukti audit $[12,13,14,15,16]$. Berbagai sistem informasi akuntansi yang tersedia saat ini kebanyakan menggunakan pendekatan sebagai aplikasi berbasis web (lihat misalnya: [16]). Dalam kaitannya dengan implementasi ADA dan penggunaan web page sebagai salah satu sumber data ini, terdapat sebuah aplikasi teknologi yang perlu diperhatikan yaitu teknik perolehan dan ekstraksi data dari web page yang dikenal dengan istilah web data extraction atau juga disebut juga sebagai web scraping $[15,17,18,19,20]$.

Pada saat auditor memerlukan data yang berasal dari web page dengan berbagai komponennya sebagai salah satu sumber bukti audit maka ia harus mengekstrasi data tersebut untuk kemudian dianalisis sesuai dengan prosedur pengujian audit yang telah ditetapkan oleh sang auditor. Jika ekstraksi data ini harus dilakukan untuk jumlah web page yang besar dan merupakan pekerjaan yang dilakukan berulang-ulang maka akan lebih efisien jika menggunakan berbagai teknik web data extraction tersebut. Artinya, auditor memerlukan sebuah teknik atau prosedur valid, reliabel dan relatif mudah penggunaannya sehingga memungkinkan untuk mengumpulkan bukti audit yang berasal dari laman web yang relevan dengan penugasan auditnya.

Untuk itu, tulisan ini dengan menggunakan perspektif design science research (lihat misalnya [21]) ingin menelaah lebih dalam bagaimana web data extraction sebagai sebuah artefak teknologi dapat dimanfaatkan oleh auditor dalam implementasi ADA. Dengan penggunaan perspektif design science research, penelitian ini menyajikan kerangka konsepsual dan praktikal terkait dengan artefak teknologi berupa teknik web data extraction yang dapat digunakan oleh auditor dalam mengimplementasilkannya. Artefak dalam konteks tulisan ini adalah berupa sebuah instantiasi (instantiation) dari penggunaan web data extraction untuk use case (lihat misalnya: [22]) yang sesuai untuk implementasi ADA [23, 24]. Kontribusi yang diharapkan dari hasil penelitian ini adalah tersedianya sebuah referensi praktis yang dapat digunakan oleh auditor dalam mengaplikasikan web data extraction untuk memperoleh bukti audit untuk kemudian dapat dielaborasi, dianalisis, dan diuji lebih lanjut sesuai dengan program audit yang telah disusunnya.

Setelah bagian pertama yang menguraikan latar belakang masalah, selanjutnya sistematika tulisan adalah sebagai berikut. Bagian kedua akan berisi tentang tinjauan literatur termasuk hasil penelitian sebelumnya yang relevan dengan topik tulisan ini. Selanjutnya, bagian ketiga akan menyajikan pendekatan penelitian. Bagian keempat akan memaparkan temuan hasil penelitian dan pembahasaannya. Terakhir, bagian kelima akan menyajikan kesimpulan dan rekomendasi.

\section{TINJAUAN LITERATUR}

Bagian ini akan memaparkan berbagai teori, konsep, kerangka pemikiran dan juga penelitian terdahulu yang berkaitan dengan analitika data audit dan web data extraction. Berdasarkan tinjauan literatur tersebut akan diajukan kerangkan pemikiran. Kedua hal tersebut diharapkan dapat menjadi dasar pemahaman yang nantinya digunakan untuk mendiskusikan temuan penelitian.

\section{A. Analitika Data Audit}

Istilah analytics pada awalnya berupa kata, bukan frasa, diperkenalkan oleh [25]. Definisinya adalah penggunaan yang ekstensif atas data, analisis statistika dan kuantitatif, model eksplanatori dan prediktif, dan manajemen berbasis-fakta untuk mendukung pengambilan keputusan beserta tindakannya. Analitika adalah kerangka praktis yang dapat digunakan untuk mendapatkan berbagai wawasan (insights) dari sekumpulan data yang dapat diakses oleh organisasi. Dalam perkembangannya, penggunaaan istilah analytics ini menjadi sebuah frasa bergantung pada kata yang menyertainya [26]. Berdasarkan kata yang menyertai tersebut dapat dibedakan analitika atas fungsi bisnis ataupun objek yang dianalisis. Untuk kelompok pertama muncul istilah enterprise analytics, business analytics, marketing analytics, atau accounting analytics [3]. Sementara itu untuk kelompok kedua dikenal beberapa istilah seperti: data analytics, network analytics, big data analytics, web analytics, text analytics, dan sebagainya [27].

Terdapat sedikit perbedaan pendapat tentang makna dan penggunaan istilah analytics dengan analysis. Analytics (analitika) adalah kerangka pengetahuan yang terkait dengan analisis. Sedangkan analysis (analisis) adalah tindakan untuk 
mengaplikasikan analytics sesuai dengan bidang atau tema bisnis tertentu [28, 29]. Pada sisi lain, terdapat beberapa praktisi yang cenderung menggunakan istilah analytics dan analysis ini sebagai padanan dan merupakan istilah yang dapat dipertukarkan (lihat misalnya: [2] atau [30]).

Dalam situasi tertentu, untuk menekankan makna muncul pula frasa dengan menggabungkan fungsi bisnis dan objek analisisnya seperti pada istilah Analitika Data Audit (ADA). Referensi [8] menyatakan bahwa ADA adalah seni dan ilmu untuk menemukan, menganalisis pola, mengidentifikasi ketidakwajaran (anomali), dan mengekstraski informasi lainnya sekumpulan data atau hal lain yang berkaitan dengan suatu pekerjaan audit melalui analisis, pemodelan, dan visualisasi untuk kepentingan perencanaan atau pelaksanaan audit. Sedangkan [31] memberikan pengertian ADA sebagai penemuan pola data yang dapat meningkatkan pengetahuan untuk kemudian dikomunikasikan kepada pihak yang memerlukan. Sementara itu, [32] memberikan definisi ADA sebagai proses dan aktivitas yang dirancang untuk mendapatkan dan mengevaluasi dengan tujuan untuk mengidentifikasi risiko kunci dan kesalahan, meningkatkan efisiensi bsinis, memverifikasi efektivitas proses dan membantu pengambilan keputusan bisnis.

Paragraf 1.14 panduan ADA-AICPA menyatakan ADA bahwa dapat digunakan oleh auditor pada semua tahapan audit. Selanjutnya, paragraf 2.08 menjelaskan urutan langkah yang sebaiknya dilakukan oleh auditor dalam menggunakan ADA yaitu: (1) tetapkan rencana penggunaan ADA; (2) akses dan perisapan data yang akan digunakan; (3) pertimbangkan relevansi dan reliabilitas data yang digunakan; (4) laksanakan ADA; (5) evaluasi hasilnya dan mengambil kesimpulan terkait dengan tujuan dan manfaat dari pelaksanaan ADA. Perlu diperhatikan pula paragraf 1.8 - 1.9 yang menyatakan perlunya auditor mempertimbangkan teknik dan perangkat yang digunakan untuk melaksanakan ADA sesuai dengan sasaran penggunaannya. Hal krusial sehubungan dengan pelaksanaan ADA tentu saja adalah akses data. Paragraf 1.29 secara ringkas menjelaskan bahwa karena auditor akan menghadapi berbagai macam platform pengolahan data maka auditor perlu mempersiapkan beberapa pendekatan akuisisi data agar ia dapat melaksanakan ADA. Pendekatan tersebut adalah: (1) impor data secara native dari aplikasi pengolahan data milik auditor; (2) ekstraksi data dengan perangkat lunak audit. Untuk mendapatkan perbandingan dengan panduan AICPA tersebut, tulisan ini merujuk juga pendekatan pengambilan data dalam pekerjaan audit yang dipaparkan oleh [10], yaitu: (1) interactive export, fitur untuk menyalin data sumber dalam format asli (native)-nya; (2) batch processes, fungsi dalam sistem aplikasi yang menghasilkan keluaran tertentu secara berkala sehingga data ini dapat digunakan langsung oleh auditor; (3) report writer, fitur untuk memilih kolom dan baris data tertentu untuk kemudian dijadikan keluaran berupa file; (4) Extract-Transform-Load (ETL), fungsi untuk mengambil data tertentu dan menghasilkan data keluaran dengan format data yang kompatibel dengan perangkat auditor; (5) web services atau Application Programming Interface (API), fitur untuk menghasilkan keluaran dengan menggunakan protokol konunikasi data tertentu dan keluran datanya dalam format tertentu, terutama XML; (6) spooled reports, fungsi untuk menghasilkan file laporan dengan tampilan/format sebagaimana jika laporan tersebut dicetak menggunakan kertas. Dalam hemat penulis, daftar tersebut masih belum mencakup satu alternatif lagi pendekatan akuisisi data yang menggunakan laman web sebagai sumber datanya, yaitu web data extraction. Uraian selanjutnya dalam tinjauan literatur ini akan menjelaskan pengertian web data extraction sehingga diperoleh dasar pemahaman mengapa pendekatan ini dapat menjadi alternatif akuisisi data dalam pelaksanaan ADA.

\section{B. Web Data Extraction}

Merujuk Kamus Besar Bahasa Indonesia, istilah "web" sudah diserap ke dalam bahasa Indonesia yang artinya adalah "sistem untuk mengakses, memanipulasi, dan mengunduh dokumen hipertaut yang terdapat dalam komputer yang dihubungkan melalui internet" (https://kbbi.kemdikbud.go.id/entri/web). Web data extraction adalah penggunaan perangkat teknologi untuk secara otomatis mengekstrasi dan mengorganisasikan data yang berasal dari web sehingga kemudian data tersebut dapat dianalisis lebih lanjut [17, 33]. Beberapa istilah lain yang sering dipertukarkan dengan istilah ini adalah web scraping, web crawling ataupun web harvesting [34]. Web data extraction artinya menggunakan perangkat lunak yang digunakan untuk mengakses laman web untuk kemudian mengekstraksi data tertentu dari laman tersebut untuk diolah kembali atau disimpan menjadi format lainnya, seperti spreadsheet, database atau file, sebagaimana keinginan penggunanya. Sementara itu, web scraping diartikan sebagai tindakan untuk "mengelupas" data tertentu dari sekelompok laman web yang sesuai dengan kebutuhan penggunanya.

Pendekatan ini berbeda dengan web services atau API, dan juga berbeda dengan pendekatan yang disebut dengan Electronic Data Interchange (EDI). Kedua pendekatan terakhir (API dan EDI) ini lebih menekankan pada adanya suatu protokol yang harus terlebih dulu ditetapkan terlebih dulu oleh setiap pihak yang terlibat pertukaran data, baik pertukaran yang dilakukan secara real time atau batchprocessing [35]. Sementara itu dari sudut pandang web data extraction, apapun format datanya selama dalam yang tersedia dalam laman web, sepanjang dapat dikenali HTML-tag dan format data/file-nya maka hal ini sudah menjadi elemen data yang dapat diekstraksi atau "dikelupas"/"dikerik" (scraped) dari laman web yang menjadi sumber data, untuk kemudian diolah dan dianalisis lebih lanjut. Situasi yang demikian ini akan memberikan alternatif baru terkait dengan bagaimana auditor dapat memperoleh data untuk penerapan ADA dalam penugasan auditnya.

Prinsip kerja utama web data extraction adalah memisahkan antara HTML-element (disebut juga dengan HMTL-tag atau meta-data yang merupakan elemen agar suatu laman web dapat berfungsi dengan baik) dengan dataelement (elemen ini merupakan data yang akan diekstraksi dan diolah oleh pengguna laman web). Jika kedua hal tersebut sudah dapat dipisahkan maka data-element itulah yang akan disimpan ke tempat penyimpanan tertentu seperti 
spreadsheet, flat file, ataupun database untuk kemudian dapat diolah lebih lanjut.

Menurut penulis, terdapat dua metode utama untuk melakukan web data extraction, yaitu non-pemrograman (non-coding) dan pemrograman (coding). Untuk metode nonpemrograman telah terdapat beberapa paket perangkat web data extractor seperti import.io, FMiner, ParseHub, webscraper.io, Microsoft Excel dengan add-in Power Query, ataupun Microsoft Power BI Desktop [36, 37]. Setiap metode bekerja dengan prinsip kerja yang sudah dijelaskan tadi, yaitu memisahkan HTML-element dengan data-element. Metode ini dapat bekerja dengan optimal untuk laman web yang menggunakan URL dengan tipe GET dan tidak mengandung JavaScript yang kompleks [18, 38]. Sementara itu, untuk metode pemrograman memerlukan bahasa pemrograman yang dapat membaca dan mengenali berbagai komponen laman web (HTML). Saat ini bahasa pemrograman yang populer digunakan untuk web data extraction antara lain adalah Python, R, PHP, Java, ataupun VBA-Excel [17, 20, 39, 40]. Metode ini akan lebih optimal untuk mengekstraksi data yang berasal dari laman web dengan tipe POST terlebih jika di dalamnya terdapat komponen JavaScript yang kompleks

Hal lain yang perlu dipertimbangkan dalam melakukan web data extraction adalah aspek legalitas. Aspek ini perlu mendapatkan perhatian dan pertimbangan dalam melakukan web data extraction. Beberapa pendapat terkait ini (lihat misalnya: [16, 41, 42, 43]) web data extraction harus dilakukan dengan membaca syarat dan ketentuan yang dinyatakan oleh pemilik situs atau laman web. Hal ini untuk menjaga munculnya risiko tuntutan hukum dari pengelola situs atau laman web yang datanya diekstraksi. Untuk itu, [13] mengajukan beberapa pertimbangan untuk memitigasi risiko tersebut: (1) apakah web scraping atau web crawling secara eksplisit dilarang dalam "syarat dan ketentuan" untuk mengakses situs web tersebut?; (2) apakah data yang akan diambil secara eksplisit dinyatakan sebagai copyrighted materials?; (3) apakah ada penggunaan data yang ilegal?; (4) apakah aktivitas web scraping atau web crawling berpotensi menyebabkan kerusakan pada situs atau server web? (5) apakah terdapat pelanggaran terhadap privasi seseorang? (6) apakah terdapat data yang terkait sesuai yang konfidensial? (7) apakah pengambilan data ini berakibat penurunan nilai dari pemilih situs web yang data di-scraped? Berkaitan dengan pekerjaan audit yang membutuhkan aktivitas web data extraction dengan tujuan situs web yang berada di luar kendali auditi maka sangat disarankan agar auditor berkomunikasi secara formal dengan pemilik situs web untuk mendapatkan izin untuk melakukan ekstraksi data.

\section{METODE PENELITIAN}

Pendekatan penelitian, merujuk [44], adalah istilah untuk menggambarkan keterkaitan antara paradigma peneliti atas masalah penelitian, rancangan dan strategi yang menjelaskan bagaimana penelitian dilaksanakan, serta metode penelitian yang terdiri dari teknik pengumpulan dan analisis data. Salah satu paradigma yang disebutkan adalah pragmatisme, yaitu pandangan yang menekan aplikasi sebuah konsep untuk tujuan pemecahan masalah. Paradigma ini berbeda dengan positivisme yang menekankan hasil penelitian untuk tujuan penjelasan dan prediksi ataupun pasca-positivisme (postpositivism) yang cenderung menitikberatkan pada pemahaman-mendalam (verstehen) dari sebuah fenomena dengan konteks situasi alamiahnya. Menurut [45] dalam paradigma pragmatisme, segala sesuatu akan dianggap benar manakala mempunyai kegunaan yang bersifat praktis dalam kehidupan. Prinsip dasar kebenaran bagi pragmatisme adalah segi kebermanfaatannya.

Merujuk kepada batasan tersebut, pendekatan yang dipilih oleh penelitian ini diuraikan sebagai berikut. Pertama, paradigma yang digunakan adalah pragmatisme dalam konteks design science. Paradigma ini dipilih karena sejalan tujuan suatu penelitian untuk memecahkan masalah (problem solving, lihat misalnya $[25,28,46,47])$ dengan mengajukan rancangan sebuah artefak teknologi. Sebagaimana dikemukakan oleh [48], artefak dalam paradigma design science adalah “... designing and building a new, novel artifact such as a computer application program, development methodology, or model is a contribution to knowledge ... ". Kedua, rancangan penelitian adalah design research dengan strategi penelitian pengembangan model dan instantiasi berupa artefak yang berkaitan dengan implementasi web data extraction dalam analitika data audit (lihat misalnya: $[49,50]$ ). Ketiga, teknik pengumpulan dan analisis data yang digunakan adalah studi dokumentasi dengan analisis data kualitatif berupa kesesuaian antara teknologi yang tersedia dengan permasalahan yang akan diselesaikan. Artefak sebagai hasil penelitian dengan rancangan design research, merujuk [51] dan juga [52] diartikan sebagai: (1) konstruksi (constructs): vocabulary and symbols, bahasa atau ungkapan untuk memformulasikan fenomena; (2) model (abstractions and representations, abstraksi atau penyederhanaan dari entitas di dunia nyata untuk mengurangi kompleksitas; (3) metode (methods): algorithms and practices, panduan untuk penentuan solusi atas suatu masalah, langkah demi langkah yang merujuk kepada model yang telah dibuat; (4) instantiasi (instantiations): implemented and prototype systems, implementasi dari konstruksi, model atau metode untuk penyelesaian masalah nyata yang sedang dihadapi. Penelitian ini bertujuan untuk menghasilan artefak teknologi yang dapat digunakan untuk memperbaiki implementasi ADA sebagai bagian dari disiplin audit. Untuk menghasilkan sebuah artefak berbasis TIK, [53] memberikan panduan langkah-langkah sebagaimana dipaparkan dalam Tabel 1.

Tabel 1. Langkah Pembentukan Artefak Teknologi: Web Data Extraction Untuk Implementasi ADA

\begin{tabular}{ll}
\hline Langkah-Langkah & Aplikasi Dalam Penelitian Ini \\
\hline (1) identifikasi dan & Auditor yang menggunakan ADA \\
deskripsi yang jelas dari & perlu mempersiapkan berbagai teknik \\
problem organisasional & akuisisi data termasuk mengakuisisi \\
yang relevan & $\begin{array}{l}\text { data dari aplikasi berbasis web yang } \\
\text { tidak menyediakan web services }\end{array}$ \\
& ataupun protokol integrasi data \\
& lainnya seperti EDI, Application \\
\hline
\end{tabular}




\begin{tabular}{|c|c|}
\hline Langkah-Langkah & Aplikasi Dalam Penelitian Ini \\
\hline & $\begin{array}{l}\text { Programming Interface (API), atau } \\
\text { koneksi ke dalam basisdata }\end{array}$ \\
\hline $\begin{array}{l}\text { (2) bukti bahwa belum } \\
\text { ada solusi yang } \\
\text { memadai dan tambahan } \\
\text { pengetahuan yang akan } \\
\text { dihasilkan }\end{array}$ & $\begin{array}{l}\text { belum ada ada konstruksi, model, } \\
\text { metode atau instantiasi yang secara } \\
\text { eksplisit menyatakan penggunaaan } \\
\text { web data extraction sebagai bagian } \\
\text { dari ADA }\end{array}$ \\
\hline $\begin{array}{l}\text { (3) pengembangan dan } \\
\text { penyajian dari artefak } \\
\text { baru (constructs, } \\
\text { models, methods or } \\
\text { instantiations) yang } \\
\text { menyelesaikan masalah } \\
\text { yang sedang dihadapi }\end{array}$ & $\begin{array}{l}\text { Upaya untuk mengembangkan } \\
\text { konstruksi, model, metode atau } \\
\text { instantiasi dalam hal ini adalah web } \\
\text { data extraction dapat digunakan } \\
\text { menjadi salah satu alternatif akuisasi } \\
\text { data untuk kekpentingan ADA dalam } \\
\text { suau pekerjaan audit }\end{array}$ \\
\hline $\begin{array}{l}\text { (4) evaluasi yang } \\
\text { menyeluruh atas } \\
\text { manfaat yang } \\
\text { didapatkan dari artefak } \\
\text { yang dikembangkan }\end{array}$ & $\begin{array}{l}\text { Uji coba dalam format instansiasi dari } \\
\text { web page tertentu yang menyediakan } \\
\text { data yang dapat dikases secara bebas } \\
\text { oleh publik untuk kemudian dapat } \\
\text { digunakan sebagai bagian dari ADA }\end{array}$ \\
\hline $\begin{array}{l}\text { (5) pernyataan adanya } \\
\text { nilai tambah terhadap } \\
\text { praktik dan akumulasi } \\
\text { pengetahuan }\end{array}$ & $\begin{array}{l}\text { Hasil penelitian ini diharapan dapat } \\
\text { menjadi tambahan referensi untuk: (1) } \\
\text { praktik audit berupa artefak dalam } \\
\text { bentuk instantiasi penggunaan web } \\
\text { data extraction untuk akusisi data } \\
\text { yang berasal dari laman web; (2) } \\
\text { adanya kerangka pemahaman } \\
\text { kedudukan web data extraction dan } \\
\text { ADA dalam lanskap pengetahuan } \\
\text { audit }\end{array}$ \\
\hline $\begin{array}{l}\text { (6) penjelasan atas } \\
\text { implikasi terhadap } \\
\text { praktik manajemen }\end{array}$ & $\begin{array}{l}\text { Manajemen audit (Chief Audit } \\
\text { Executive/CAE) ataupun auditi dapat } \\
\text { memamahami keberadaan web data } \\
\text { extraction dalam kaitannya dengan } \\
\text { ADA sehingga penugasan audit dapat } \\
\text { berjalan lebih efektif }\end{array}$ \\
\hline
\end{tabular}

\section{EKSPERIMEN DAN ANALISIS}

Bagian diskusi akan diawali dengan ringkasan temuan penting penelitian. Selanjutnya, akan diberikan penjelasan lebih detil dari temuan tersebut. Ringkasan temuan penting adalah sebagai berikut. Pertama, dengan artefak yang disusun berupa konstruksi, model, metode dan instantiasi dikembangkan dengan mengacu pada "Guide to Audit Data Analytics" yang diterbitkan oleh AICPA [6]. Argumentasi atas pilihan ini adalah sampai dengan kajian ini dilakukan panduan tersebut dapat dikatakan sebagai yang paling komprehensif dalam mengarahkan penggunaan ADA sebagai bagian dari pekerjaan audit, khususnya audit laporan keuangan historis. Sebagai perbandingan, panduan lain yang sudah terbit adalah "Data Analytics - A Practical Approach" [37] yang dalam pandangan penulis masih belum komprehensif dan tidak lagi menggambarkan situasi terkini. Walaupun demikian, masih terdapat bagian menarik yaitu Appendix B (hal. 15) tentang Top 10 Types of Analytic Logics yang tetap relevan sampai dengan saat ini. Kedua, artefak dalam bentuk instantiasi dapat dilakukan dengan menggunakan beberapa perangkat lunak seperti: webscraper.io, VBA-Selenium berbasis Microsoft Excel, ataupun Power BI Desktop.
A. Kedudukan Web Data Extraction Dalam ADA: Pengembangan Artefak

Merujuk [23], pengembangan artefak dalam paradigma design science meliputi konstruksi, model, metode dan instantiasi. Untuk itu, penulis akan menggunakan kerangka penggunaan ADA yang dikembangkan oleh AICPA sebagai dasar untuk menyusun artefak. Gambar 1 mengilustrasikan kedudukan berbagai artefak yang terkait dengan pemanfaatan web data extraction dalam ADA. Konstruksi adalah kerangka pemikiran bahwa web data extraction belum secara eksplisit disebut sebagai salah satu teknik akuisisi data dalam ADA jika auditor menghadapai sumber data yang berupa aplikasi berbasis web. Model yang diajukan adalah sebagaimana disajikan dalam Gambar 1. Metode yang dapat digunakan penggunaan berupa: (1) perangkat lunak web data extractor (misalnya: webscraper.io), (2) bahasa pemrogrman dengan tambahan modul tertentu (misalnya VBA Microsoft Excel dengan tambahan Selenum-Basics atau Python dengan Selenium); (3) perangkat lunak analitika data yang dilengkapi dengan fitur ekstraksi data dari laman web (misalnya Power Query). Instantiasi adalah penerapan dengan menggunakan berbagai perangkat lunak tersebut untuk melakukan web data extraction sehingga terbentuk data yang akan dianalisis dengan kerangka praktik ADA.

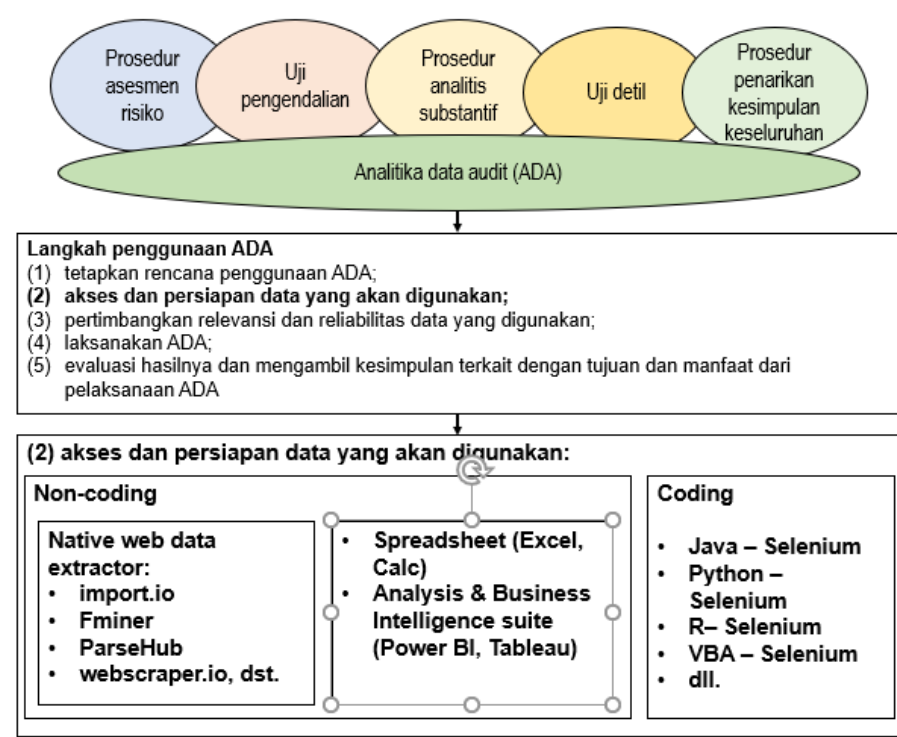

Gambar 1. Diagram Blok Web Data Extraction Untuk ADA (Dimodifikasi dari [6:5] dan [52])

\section{B. Instantiasi web data extraction dalam ADA}

Instansiasi (instantiation) adalah realisasi sebuah artefak sehingga ia dapat menjadi bagian dari lingkungan nyatanya [21]. Ibaratnya resep masakan, maka pada saat seseorang menggunakan resep itu menjadi sebuah hidangan yang dapat disantap maka itulah instantiasi. Dalam konteks penelitian ini berupa penerapan teknik web data extraction dengan perangkat tertentu yang dipilih sehingga dapat terbentuk data yang dapat dianalisis dengan kerangka ADA. Agar kasus yang dibahas dalam instantiasi ini tidak menjadi terlalu kompleks, penulis memilih data kurs pajak yang disediakan oleh Badan Kebijakan Fiskal (BKF) di URL: 
https://fiskal.kemenkeu.go.id/informasi-publik/kurs-pajak. URL (Uniform Resource Locator, lihat misalnya https://kb.iu.edu/d/adnz) atau link adalah posisi data di jaringan web (internet/intranet). Laman web ini dipilih karena sesuai dengan sifat informasinya yang tersedia untuk publik secara luas dan relatif relevan dengan bukti audit. Berdasarkan contoh kasus yang demikian ini diharapkan dapat memberikan gambaran bagaimana auditor dapat menggunakan teknik web data extraction sebagai bagian dari pekerjaan auditnya. Sebagaimana dijelaskan dalam Gambar 1, instantiasi tersebut dilakukan dengan cara (1) akses dan perisapan data yang akan digunakan; (2) penentuan teknik ekstraksi (coding atau non-coding) berdasarkan struktur laman web yang diperoleh; (3) eksekusi perintah ekstraksi baik dengan teknik coding ataupun non-coding.

Langkah awalnya adalah pemahaman struktur laman web. Laman web ini dapat diakses dengan memasukkan parameter tanggal kurs pajak yang dikehendaki secara langsung ke dalam URL-nya ataupun menggunakan menu point-and-click yang tersedia di laman web tersebut. Langkah selanjutnya bergantung pada kebutuhan informasi yang akan diekstraksi. Jika auditor hanya akan mengekstraksi data untuk beberapa tanggal saja maka dia bisa menggunakan mengganti parameter tanggal dengan point-and-click dan kemudian menggunakan teknik non-coding dengan cara block-copypaste dari informasi yang diinginkan ke dalam perangkat lunak spreadsheet seperti Microsoft Excel. Namun apabila auditor membutuhkan data kurs ini dalam untuk kurun waktu yang relatif panjang, tiga bulan misalnya maka dia harus menggunakan teknik coding.

Berdasarkan pemahaman terhadap struktur laman web yang akan diekstraksi sebagaimana telah diuraikan di atas maka penulis mengajukan dua teknik yang akan diinstantiasi. Cara pertama, metode non-coding dengan block-copy and paste dari data ke dalam Microsoft Excel. Langkah-langkah yang dilakukan tersebut nungkin sudah sangat populer bagi para auditor. Ringkasan prosedur ekstraksi data dengan teknik ini adalah: (1) menentukan URL sumber data; (2) block data yang diinginkan, kemudian copy; (3) lalu paste (dengan pilihan Special) di file Excel (XLSX) yang telah dipersiapkan untuk menampung data; (4) kemudian pilih sebagai HTML; (5) data hasil ekstraksi dapat digunakan untuk pengolahan dan analisis lebih lanjut. Teknik ini sederhana dan mudah dilakukan, dan cocok untuk strukur laman web tabular dengan jumlah laman web yang relatif sedikit. Jika auditor harus menghadapi data yang tersebar di banyak laman web, teknik ini tidak akan memadai lagi sehingga memerlukan teknik yang lain.

Sementara itu cara kedua, auditor dapat menggunakan metode modified-URL-copy. Atas URL yang di-copy tersebut akan di-paste di perangkat web data extractor. Teknik ini bisa dilakukan dengan menggunakan perangkat web data extractor seperti FMiner, import.io, atau webscraper.io ataupun beberapa perangkat transformasi data. Tulisan ini melakukan uji coba dengan menggunakan perangkat transformasi data berupa Power Query yang merupakan fitur di dalam perangkat Excel ataupun Power BI. Teknik ini jika dibandingkan metode pertama akan lebih mudah jika auditor melakukan ekstraksi data terhadap banyak laman web karena teknik ini memungkinkan ada iterasi atas perhatian pengambilan data dengan URL yang berubah-ubah sesuai dengan parameter yang dimasukkan ke dalam URL. Dengan catatan, teknik ini tidak bisa digunakan terhadap situs web yang menyimpan parameter pencarian dalam URL-nya dengan metode POST atau laman web yang mengandung CSS maupun JavaScript (lihat misalnya: [41, 42]). Secara teknis, cara ini memerlukan beberapa langkah untuk mengubah script yang telah dibuatkan secara otomatis oleh Power Query dengan cara menambahkan Invoke Custom Function dan membuat sebuah Table yang isinya adalah parameter tanggal kurs pajak sesuai dengan rentang waktu yang diinginkan.

Cara ketiga adalah dengan mengggunakan bahasa pemrograman (coding). Teknik akan lebih kompleks jika dibandingkan dengan yang pertama dan kedua. Jika auditor menghadapi data yang tersebar di banyak laman web dan URL-nya menggunakan metode POST maka teknik yang digunakan adalah dengan membuat kode program (coding) dengan bahasa tertentu. Penelitian ini menggunakan VBASelenium untuk mengambil data kurs pajak dari situs web sebagaimana yang digunakan teknik pertama dan kedua. Perbedaannya, teknik ini akan mengambil secara berulang untuk setiap tanggal pemberlakuan kurs pajak selama satu tahun untuk semua jenis mata uang. Teknik ini tidak akan diuraikan detil prosedur karena memang cukup rumit dan panjang. Pada prinsipnya adalah jika struktur laman web yang akan diekstraksi semakin komples (misalnya di laman web tersebut terdapat CSS ataupun JavaScript) maka web data extraction harus menggunakan teknik pemrograman (coding). Atas penggunaan ketiga teknik tersebut, penulis membuat rangkuman untuk membandingkan ketiga. Peenulis telah mempraktikan teknik dengan pemrograman tersebut dan dapat mengekstraksi data dari laman web yang strukturnya lebih kompleks. Tabel 2 menyajikan perbandingan antara ketiga teknik web data extraction yang sudah diuraikan di atas.

Tabel 2. Perbandingan Perangkat Web Data Extraction dan Fitur Pentingnya: Instantiasi Dengan Beberapa Perangkat Perangkat Catatan Dari Kasus Uji Coba Instantiasi

Microsoft 1) block-copy-paste dari suatu web page

Excel 2) hasil ekstraksi data berupa file XLSX

3) tidak memerlukan ketrampilan programming

4) terdapat keterbatasan jika data yang dibutuhkan ada dalam banyak laman web karena harus melakukan perulangan kegiatan yang cenderung membosankan dan dan rawan kesalahan

Power 1) merupakan add-in Power Query untuk dalam

Query Microsoft Excel 2013, atau Get \& Transform dalam Microsoft Excel 2016, atau Get Data dalam Microsoft Power BI Desktop

2) terdapat fitur copy and paste URL web page yang akan diekstraksi dan sampai dengan tingkat kompleksitas tertentu HTML-tag telah dikenali

3) dapat untuk mengekstraksi laman web dengan tipe GET dengan data yang terbagi dalam beberapa halaman (pagination)

4) hasilnya dapat berupa file XLSX atau CSV 


\begin{tabular}{ll}
\hline Perangkat & \multicolumn{1}{c}{ Catatan Dari Kasus Uji Coba Instantiasi } \\
\hline Selenium- & 1) menggunakan Selenium yang tersedia untuk \\
based & berbagai versi bahasa pemrograman, misalnya \\
& VBA, Python, R atau Java \\
& 2) memerlukan class Selenium Basics, dapat diunduh \\
& sesuai dengan bahasa pemrograman yang dipilih, \\
& misalnya VBA-Selenium dapat diunduh secara \\
& bebas dari di \\
& https://florentbr.github.io/SeleniumBasic/ \\
3) hasilnya dapat berupa file XLSX atau CSV
\end{tabular}

sumber: Hasil analisis dan uji coba penulis

Secara teknis, web data extraction dapat dilakukan dengan beberapa perangkat. Tabel 1 akan memaparkan berbagai perangkat yang dapat digunakan untuk web data extraction. Selain perangkat yang dicontohkan ini tentu saja masih sangat banyak sekali perangkat yang beredar dan ditawarkan oleh para vendornya ataupun hasil penelitian yang sudah dipublikasikan (lihatnya misalnya [42]). Pemilihan perangkat web data extraction dalam penelitian ini dilakukan oleh penulis secara arbitrer dan memang secara praktik nyata penulis telah menggunakan perangkat tersebut untuk pelaksanaan ADA. Perangkat tersebut digunakan sematamata karena penulis pernah mencoba menggunakan aplikasi ini untuk mempraktikkan web data extraction. Hasil ekstraksi dari berbagai perangkat yang dicontohkan ini secara umum sudah dapat diolah dengan oleh perangkat lunak audit yang digunakan oleh auditor. Isu pengolahan dan analisis data sudah berada di luar cakupan teknik web data extraction yang berada pada tahap akses dan persiapan sedangkan analisis data terletak pada tahap pelaksanaan ADA (lihat kembali penjelasan terkait Paragraf 2.08 panduan ADA-AICPA ).

\section{KESIMPULAN}

Web data extraction merupakan salah satu alternatif teknik akuisasi data yang dapat digunakan oleh auditor untuk mengimplementasikan ADA sebagai bagian dari suatu pekerjaan audit yang semakin hari semakin menghadapi banyak tantangan berupa sumber bukti audit dalan bentuk data elektronik termasuk yang tersimpan dalam aplikasi berbasis web. Hasil dari instansiasi proses data extraction dengan menggunakan perangkat Excel, Power Query ataupun VBASelenium berupa file yang dapat diolah lebih lanjut oleh auditor dengan berbagai teknik pengujian audit sehingga didapatkan temuan dan kesimpulan hasil audit. Penelitian ini mempunyai keterbatasan yaitu hanya menggunakan tiga jenis perangkat ekstraksi data dan uji coba masih pada tahap proofof-concept, belum dilaksanakan pada penugasan audit yang sesungguhnya.

Untuk mendapatkan kesimpulan bahwa artefak yang ditemukan tersebut memanglah robust dan sesuai dengan kebutuhan para auditor, masih memerlukan pembuktian dengan mengunakannya pada penugasan pekerjaan audit yang sebenarnya, terutama yang menggunakan aplikasi berbasis web sebagai salah satu sumber datanya. Karena masih sedikitnya pembahasan tentang teknologi berbasis web secara umum untuk kepentingan praktik audit (dan juga akuntansi secara lebih luas) di Indonesia, penelitian ini menyarankan agar para akademisi dan praktisi di bidang di ini dapat mengembangkan sebuah area riset yang berkaitan dengan tema web data extration sebagai bagian dari tema riset teknologi berbasis web untuk kepentingan pengembangan konsepsual dan praktikal dalam disiplin audit.

\section{REFERENSI}

[1] Coderre, D. (2015). Letting the Data tell the Story, presented at the IIA Puget Sound Chapter [Online]. Diakses dari: https://chapters.theiia.org/puget-sound/ ChapterDocuments/Data\%20Analytics\%20-20AM.pdf.

[2] Cascarino, R.E. (2017). Data Analytics for Internal Auditors. CRC Press.

[3] Bumgarner, N. \& Vasarhelyi, M.A. (2015). Continuous Auditing-A New View CPA. Audit Analytics and Continuous Audit: Looking Toward the Future. New York, NY, USA: AICPA, pp. 3-52.

[4] PwC (2017). How Data is Transforming Internal Audit's Role in the Organization, Presented at the April IIA Meeting [Online]. Diakses dari: https://www.pwccn.com/en/risk-assurance/publications /transforming-ia-through-data analytics.pdf.

[5] FRC (2017). The Use of Data Analytics in the Audit of Financial Statements. London: Financial Reporting Council (FRC).

[6] AICPA (2017). AICPA Guide to Audit Data Analytics. New York: American Institute of Certified Public Accountants, Inc. (AICPA).

[7] EY (2015). How Big Data And Analytics Are Transforming The Audit, EY Reporting. [Online]. Diakses dari: https://www.ey.com/en_gl/assurance/ how-big-data-and-analytics-are-transforming-the-audit.

[8] Byrnes, P.E., et al. (2015). Evolution of Auditing: From the Traditional Approach to the Future Audit. Audit Analytics and Continuous Audit: Looking Toward the Future. New York, NY, USA: AICPA, pp. 71-84.

[9] Vasarhelyi, M.A., Kogan, A. \& Tuttle, B.M. (2015). Big Data in Accounting: an Overview. Accounting Horizons, Vol. 29(2), pp. 381-396.

[10] Hasenstab, K. \& Cohen, E.E. (2014). Extracting Your Company's Data with the New Audit Data Standard, IFAC [Online]. Diakses dari: https://www.ifac.org/ system/files/uploads/PAIB/Extracting-Your-Companys -Data-with-the-New-Audit-Data-Standard-Sept2014.pdf.

[11] ICAEW. (2016). Data Analytics for External Auditors. International Accounting, Auditing \& Ethics (IAAE).

[12] Ferrara, E., Meo, P.D., Fiumara, G. \& Baumgartner, R. (2014). Web Data Extraction, Applications and Techniques: A Survey. Knowledge-Based Systems, Vol. 70, pp. 301-323, doi: 10.1016/j.knosys.2014.07.007.

[13] Krotov, V. \& Silva, L. (2018). Legality and Ethics of Web Scraping. the Twenty-fourth Americas Conference on Information Systems. New Orleans. 
[14] Krotov, V. \& Tennyson, M. (2018). Scraping Financial Data from the Web Using $\mathrm{R}$ Language. Journal of Emerging Technologies in Accounting, Vol. 15(1), doi: 10.2308/jeta-52063.

[15] Chanda, S.V. \& Arivoli, A. (2020). Web Scraping in Finance using Python. International Journal of Engineering and Advanced Technology (IJEAT), Vol. 9(5), pp. 255-262, [Online]. Available: https://www.ijeat.org/wp-content/uploads/papers/ v9i5/E9457069520.pdf.

[16] Accounting Web. (2011). Which Web Based Accounting Application? Diakses dari: https://www.accountingweb. co.uk/community/blogs/john-cotter/which-web-basedaccounting-application.

[17] Zhao, B. (2017). Web Scraping. Encyclopedia of Big Data. Springer International Publishing, pp. 326-328.

[18] Chaudhari, P.A. \& Paikrao, R.L. (2012). Web Data Extraction. IJCA Proceedings on Emerging Trends in Computer Science and Information Technology (ETCSIT2012), No. 4, pp. 13-17.

[19] Kokkoras, F., Ntonas, K. \& Bassiliades, N. (2013). DEiXTo: A Web Data Extraction Suite, pp. 9-12, doi: 10.1145/2490257.2490297.

[20] Shidore, S. (2017). On the Legality and Ethics of Web Scraping [Online]. Diakses dari: https://www.linkedin. com/pulse/legality-ethics-web-scraping-sudarshanshidore.

[21] Johannesson, P. \& Perjons, E. (2014). An Introduction to Design Science. Heidelberg: Springer.

[22] Booch, G., Rumbaugh, J. \& Jacobson, I. (1998). Unified Modeling Language User Guide. Reading, Massachusetts: Addison Wesley.

[23] Liu, Q. (2014). The Application Of Exploratory Data Analysis in Auditing [Ph.D. Thesis]. Rutgers The State University of New Jersey.

[24] Kogan, A., Mayhew, B.W. \& Vasarhelyi, M.A. (2019). Audit Data Analytics Research-An Application of Design Science Methodology. Accounting Horizons, Vol. 33, pp. 69-73.

[25] Davenport, T.H. \& Harris, J.G. (2007). Competing on Analytics: The New Science of Winning. Harvard Business Review Press.

[26] Duan, L. \& Xiong, Y. (2015). Big Data Analytics and Business Analytics. Journal of. Management Analytics, Vol. 2(1), pp. 1-21 [Online]. doi:10.1080/23270012.2015.1020891.

[27] Richardson, V.J., Teeter, R. \& Terrell, K.L. (2019). Data Analytics for Accounting. New York: McGraw-Hill Education.

[28] Davenport, T.H. (2013). What Do We Talk About When We Talk About Analytics? Enterprise Analytics Optimize Performance, Process, and Decisions Through Big Data. New Jersey: Pearson Education, Inc., pp. 2533.

[29] Power, D.J., Heavin, C., McDermott, J. \& Daly, M. (2018). Defining Business Analytics: An Empirical Approach. Journal of Business Analytics, Vol. 1(1), pp. 40-53, doi: 10.1080/2573234X.2018.1507605.
[30] White, C. \& Imhoff, C. (2010). Advanced Analytics and Business Intelligence: Term Abuse? Diakses dari: http://www.b-eye-network.com/view/13797.

[31] Lambrecht, A.J., Laurent, J.E., Millar, R.B. \& Sparks, D.E. (2011). Data Analysis Technology. Florida, USA: Institute of Internal Auditors.

[32] Pett, J., Barnard, D., Agarwal, V. \& Miller, S. (2013). The Data Conundrum Finding Your Path With Data Analytics [Online]. Diakses dari: https://cdn.cfo.com/ content/uploads/2013/12/PwCs-Internal-Audit-

Analytics-Conundrum-Webcast-12-5-13.pdf.

[33] ISACA. (2011). Data Analytics-A Practical Approach. IL, USA.

[34] Kamanwar, N.V. \& Kale, S.G. (2016). Web Data Extraction Techniques: A Review. 2016 World Conference on Futuristic Trends in Research and Innovation for Social Welfare (Startup Conclave), pp. 15.

[35] Vargiu, E. \& Urru, M. (2013). Exploiting Web Scraping in a Collaborative Filtering Based Approach to Web Advertising. Artificial Intelligence Research, No. 2013, p. 2.

[36] Macapinlac, T. (2019). The Legality of Web Scraping: A Proposal. Federal Communications Law Journal, Vol. 71(3), pp. 399-422.

[37] Glez-Peña, D., Lourenco, A., López-Fernández, H., Reboiro-Jato, M. \& Fdez-Riverola, F. (2013). Web Scraping Technologies in an API World. Brief Bioinform, Vol. 15, doi: 10.1093/bib/bbt026.

[38] Neumann, M., Steinberg, J. \& Schaer, P. (2017). WebScraping for Non-Programmers: Introducing OXPath for Digital Library Metadata Harvesting. Code4Lib J., Vol. 38 [Online]. Diakses dari: https://journal.code4lib.org/ articles/13007.

[39] Microsoft. (2020). Get Webpage Data By Providing Examples. [Online]. Available: https://docs.microsoft. com/en-us/power-bi/connect-data/desktop-connect-toweb-by-example.

[40] Meschenmoser, P., Meuschke, N., Hotz, M. \& Gipp, B. (2016). Scraping Scientific Web Repositories: Challenges and Solutions for Automated Content Extraction, Vol. 22(9/10) [Online]. Diakses dari: http://www.dlib.org/dlib/september16/meschenmoser/0 9meschenmoser.print.html.

[41] Alex-Adrien, A. (2019). Concrete Example of Web Scraping with Financial Data. https://www.sipios.com/blog-tech/concrete-exampleof-web-scraping-with-financial-data.

[42] Sabri, I.A.A., Man, M., Bakar, W.A. \& Rose, A.N.M. (2019). Web Data Extraction Approach for Deep Web using WEIDJ. Procedia Computer Science, Vol. 163, pp. 417-426. doi: 10.1016/j.procs.2019.12.124.

[43] Josi, A., Abdillah, L.A. \& Suryayusra. (2014). Penerapan Teknik Web Scraping pada Mesin Pencari Artikel Ilmiah. Jurnal Sistem Informasi, Vol. 5(2), pp. 159-163. [Online]. Diakses dari: https://arxiv.org/ftp/arxiv/papers/1410/1410.5777.pdf. 
[44] Creswell, J.W. (2013). Research Design: Qualitative, Quantitative, and Mixed Methods Approaches. Thousand Oaks, California: SAGE Publications.

[45] Azwar, W. \& Muliono. (2019). Filsafat Ilmu - Cara Mudah Memahami Filsafat Ilmu. Jakarta: PrenadaMedia Group (Divisi Kencana).

[46] Hevner, A.R., March, S.T., Park, J. \& Ram, S. (2004). Design Science In Information Systems Research. MIS Quarterly, Vol. 28(1), pp. 75-105.

[47] Zeleti, F.A., Ojo, A. \& Curry, E. (2016). Exploring The Economic Value Of Open Government Data. Government. Information Quarterly, Vol. 33(3), pp. 535-551.

[48] Davis, G.B. (2003). Building an International Academic Discipline in Information Systems. Exploring Patterns in Information Management: Concepts and Perspectives for Understanding IT-Related Change. Stockholm, Sweden: The Economics Research Institute.

[49] Hevner, A.R., March, S.T., Park, J. \& Ram, S. (2004). Design Science in Information Systems Research. MIS Quarterly, Vol. 28(1), pp. 75-105.
[50] Iivari J. \& Venable, J.R. (2009). Action Research And Design Science Research - Seemingly Similar But Decisively Dissimilar. ECIS 2009 Proceedings, p. 73, [Online]. Diakses dari: http://aisel.aisnet.org/ ecis2009/73.

[51] Zapadka, P., Brendel, A.B. \& Kolbe, L.M. (2018). Design Science Research in Green IS: Analyzing The Past to Guide Future. the European Conference on Information Systems (ECIS) [Online]. Diakses dari: https://aisel.aisnet.org/ecis2018_rp/115.

[52] March, S.T. \& Smith, G.F. (1995). Design and Natural Science Research on Information Technology. Decision Support System, Vol. 15(4), pp. 251-266 [Online]. Diakses dari: https://www.sciencedirect.com/science/ article/pii/0167923694000412.

[53] Hevner, A.R. \& Chatterjee, S. (2010). Design Research in Information Systems Theory and Practice. New York: Springer. 